\title{
Reseña de Andújar, Andrea; D’Antonio, Débora; Gil Lozano, Fernanda; Grammático, Karin y Rosa, María Laura (compiladoras), De minifaldas, militancias y revoluciones: exploraciones sobre los 70 en Argentina, Buenos Aires, Luxemburg, 2009, 217 págs.
}

\author{
LUISINA AGOSTINI (UNL) \\ Centro de Estudios Sociales Interdisciplinarios del Litoral \\ Facultad de Humanidades y Ciencias \\ Universidad Nacional del Litoral \\ Santa Fe, Argentina \\ luisinaagostini@gmail.com
}

De minifaldas, militancias y revoluciones no ha pasado desapercibido en el panorama argentino de la historiografía sobre el pasado reciente. El libro reúne una serie de artículos sobre las experiencias femeninas en un contexto de cambios culturales y de procesos políticos particulares en la Argentina de los años de 1970. Las prácticas femeninas que se indagan, abarcan espacios diferentes pero atravesados por las nuevas significaciones del lugar de la mujer, como militante, como resistente y exiliada, como ama de casa. Resulta muy cuidado el armado de las tres partes que estructuran el texto; no obstante esta organización, los artículos que componen las secciones pueden leerse de manera independiente y se pueden realizar cruces enriquecedores para la relación entre género y política, entre aquellos artículos que pertenecen a diferentes partes.

Las experiencias femeninas están presentadas desde una visión activa del papel de la mujer permeada por las relaciones de género y de poder que se verán cuestionadas antes y durante los años '70. El contexto de movilización social internacional y nacional desde los '60 es el contexto para poder situar las nuevas subjetividades, que se irán presentando en los artículos. Al calor de las experiencias colectivas e individuales de mujeres en diálogo con hombres, con otras mujeres, como así también con autoridades, militantes, presos, presas, exiliados, exiliadas, hijos, madres, esposas, maridos, se insertan los relatos variados de experiencias que, coincidimos con las compiladoras en su prólogo, conforman una fortaleza central del esqueleto del libro.

La primera parte "Espacios de militancia y conflictividad" consta de cuatro capítulos, los mismos discuten la participación de las mujeres en la militancia política, en tanto proceso de construcción de identidades diversas según los conflictos, los lugares de acción concretos y las historias personales diferentes. Como contribución histórica a los estudios sobre la militancia y la participación de las mujeres en las organizaciones político- militares, los textos ofrecen análisis sobre los itinerarios de mujeres militantes, sobre las condiciones de su participación, sus orientaciones ideológicas, sus relaciones con el género masculino. El artículo de Marta Vassallo "Militancia y transgresión", recorre algunas de las características de lo que implicaba, en esos años, en la teoría y en la realidad ser mujer y militante. Los roles tradicionales que se cuestionaban no siempre significaban una ruptura en las prácticas militantes. Los sentidos del lugar de la mujer frente a los hombres se seguían reproduciendo al interior de los cuadros militantes, como así también imperaba la demonización de este tipo de mujer "diferente". Los ideales revolucionarios pretendidos no necesariamente incluían igualdad sexual y no discriminación. No obstante esto, muchas mujeres militantes no hicieron de su condición sexual una cuestión política que forme parte de la agenda en los cuadros de las organizaciones armadas que integraban.

Estas cuestiones son retomadas por Karin Grammático en el capítulo 2 "Ortodoxos versus juveniles: disputas en el Movimiento Peronista. El caso del Segundo Congreso de la Rama Femenina, 1971", cuando plantea las diferentes tensiones presentes en el congreso y cuáles fueron los temas tratados. ¿Cuáles fueron los alcances de los relatos peronistas en el congreso de 
1971? ¿Evidenciaban los cambios en las subjetividades de muchas militantes presentes? ¿Cómo se articulaban las generaciones presentes en el congreso? Son algunas de las problemáticas que podemos encontrar trabajadas en este artículo.

Los capítulos 3 y 4 pueden articularse a partir de la interesante propuesta de abordar las congregaciones religiosas pertenecientes al movimiento tercermundista, el impacto de la renovación conciliar y de la teología tercermundista en la vida religiosa femenina, aspectos trabajados por Claudia Touris en "Entre Marianne y María. Los trayectos de las religiosas tercermundistas en la Argentina". Este contexto de renovación religiosa se analiza a partir de las subjetividades y apropiaciones que pueden haber tenido las religiosas argentinas, es decir, aquellas congregaciones que se orientaron en un camino diferente abierto a partir del Concilio Vaticano II. La autora indaga en los conflictos en las representaciones sobre la figura de María y sobre las relaciones jerárquicas y de género presentes en la institución de la Iglesia. En tanto que las fuentes con las que trabaja corresponden a historias de vida, a experiencias relatadas, resulta muy interesante articular este trabajo con el propuesto por Luciana Seminara y Cristina Viano en "Las dos Verónicas y los múltiples senderos de la militancia: de las organizaciones revolucionarias de los años 70 al feminismo". El abordaje significativo desde la historia oral les permitió a las autoras reconstruir las historias de vida militante de dos mujeres santafesinas durante la década de los '70. La fortaleza de este trabajo, estimamos, radica en el trabajo historiográfico que pudieron construir a través de las formas de recordar de las protagonistas y los diferentes sentidos otorgados al pasado a partir de sus memorias. Como dijimos antes, podemos articular ambos capítulos porque las historias militantes de las dos Verónicas deben leerse a la luz de las transformaciones en el escenario religioso que el capítulo 3 recorre. La Doctrina Social de la Iglesia se convirtió en la matriz a partir de las cuales transitar los caminos diferentes de las protagonistas, pero atravesados los mismos, también por la experiencia del exilio.

El tratamiento del exilio, como espacio de resignificación de identidades, nos permite establecer una relación con otro de los capítulos que podemos encontrar en el libro. El capítulo 7 "El exilio como espacio de transformaciones de género", por Marina Franco, es el tercer texto de la segunda parte "Prácticas terroristas, prácticas de resistencia", concibe al exilio como una práctica represiva del terrorismo de Estado. Marina Franco indaga en las subjetivaciones que el exilio generó, en tanto, espacio activo de reconstrucción de identidades en hombres y mujeres. A partir de los relatos de exiliados en Francia, la autora indaga en las relaciones de género presentes, puntualiza en algunas de las trayectorias de las mujeres exiliadas, sus redefiniciones en un nuevo espacio "cotidiano" que implicó un aprendizaje político de nuevo tipo.

Como parte de la reconstrucción del plan disciplinador del Estado Terrorista, es que Débora D’Antonio en el capítulo 5 de esta segunda parte, se propone atender a la articulación estratégica entre lo ilegal y lo legal, es decir, entre los campos de detención y la masacre a prisioneros clandestinos y, el circuito de cárceles donde los/as presos/as políticos constituyeron un grupo particular que, parafraseando el título del capítulo, entre "rejas, gritos, cadenas, ruidos, ollas" pudieron activar la resistencia de nuevo tipo, la política en la cárcel. Resulta muy interesante y completa la minuciosa investigación que la autora realiza para reconstruir la conformación de la estrategia represiva a partir de 1974, enfatizando en el cambio que imprimieron los nuevos procedimientos de segregación y aislamiento desde 1976. Esta "ortopedia represiva", como la llama D'Antonio, se correspondió con una cultura de la resistencia, donde diferentes formas de agencia política tuvieron lugar con el objetivo de construir relaciones que permitieran, a los presos y presas, revitalizar la política aprendida fuera de la cárcel en un nuevo espacio para afrontar el encierro.

En el capítulo 6, "Mujeres en situación de prostitución como blanco del accionar represivo: el caso del Comando Moralizador Pío XII, Mendoza, 1974-1976", Laura Rodríguez Agüero propone un interesante estudio del caso de este Comando Moralizador, que identificaba como 
enemigo fundamental a las mujeres en situación de prostitución, a partir de la reivindicación de relaciones desiguales, asimétricas, que tenía a la opresión de género y clase (en tanto las prostitutas eran mujeres y generalmente pertenecían a los sectores más bajos de la sociedad mendocina), como bandera moralizadora para poder salvar del peligro al cuerpo de la nación.

La tercera parte del libro, que se titula "Representaciones, imágenes y vida cotidiana", se inicia con el texto de Andrea Andújar quien en "El amor en tiempos de revolución: los vínculos de pareja de la militancia de los '70. Batallas, telenovelas y rock and roll", recorre las disputas ideológicas de los jóvenes en torno a la popularidad de algunos bienes culturales como el rock y las telenovelas. Las letras de rock generalmente proponían rupturas diversas, un ideario que no siempre se correspondía con el mundo y las relaciones amorosas que las telenovelas de moda imponían, pero ambos, aunque contradictorios y opuestos fenómenos culturales eran consumidos por los / las jóvenes militantes de los años de 1970.

Con relación a estas cuestiones es que el capítulo 9 de Isabella Cosse presenta un análisis del nuevo modelo femenino de los años $60^{\prime}$, en el contexto de lo que la autora denomina una "revolución cultural" y en contradicción con los pretendidos ideales tradicionales de domesticidad y dominación a los que la mujer debía responder. De esta manera, su artículo "Los nuevos prototipos femeninos en los años ' 60 y '70: de la mujer doméstica a la joven «liberada»" resulta un interesante análisis de la ruptura de aquellos ideales femeninos reflejados en algunas revistas de la época, que eran consumidas por mujeres de diferentes estratos sociales, por ejemplo las revistas Para Ti y Vosotras. Estas fuentes le permiten a Cosse analizar los límites y los alcances de la nueva situación de la mujer con respecto al trabajo femenino, a la maternidad, a los métodos anticonceptivos, a las tareas domésticas, las relaciones extramatrimoniales, entre otros temas de la agenda de estas revistas.

Rebekah Pite en "¿Sólo se trata de cocinar? Repensando las tareas domésticas de las mujeres argentinas con Doña Petrona, 1970-1983", se ocupa de estudiar el prototipo femenino que representaba la cocinera en el contexto de esta "revolución cultural" a la que refería el capítulo anterior. Las críticas que desde el feminismo se realizaron hacia la postura apolítica, tradicional en los roles domésticos, no revolucionaria ni polémica de Petrona son analizadas por la autora, quien también hace mención a la revista Para Ti como un espacio de publicación de las recetas acorde al tono de la mujer moderna en la cocina fácil.

A diferencia con los capítulos de esta tercera parte del libro que estuvimos reseñando, pero a tono con la temática de las representaciones e imágenes, es que podemos encontrar el texto de María Laura Rosa, "Rastros de la ausencia. Sobre la desaparición en la obra de Claudia Contreras". La autora quien se especializa en el estudio del arte y feminismo se propone analizar la obra de la artista Claudia Contreras, quien a lo largo de sus trabajos, desde mitad de la década de los ' 80 , interviene en diferentes espacios culturales creando obras sobre la problemática de los desaparecidos con el objetivo de interpelar al espectador y despertar la memoria desde el presente. A través de estos análisis Rosa plantea la significativa utilización que realiza la artista de elementos de la vida cotidiana en sus obras, sus diferentes disposiciones tendrán como resultado muestras con huellas del pasado de manera poética significando el horror del genocidio.

En resumen, el libro propone una perspectiva muy fructífera al problematizar la historia argentina de las décadas de 1960-70, a partir del interés por la participación de las mujeres como protagonistas de la historia de esos años. No en vano, sus prácticas merecen un tratamiento historiográfico que, a lo largo de los diversos capítulos, abonan temáticas complejas para explicar las razones de sus acciones y la pluralidad de sus voces, de cara a las relaciones de género construidas y (re)construidas, en pos de procurar nuevas preguntas. La senda en la que se inscribe el texto ha continuado con nuevas exploraciones, pero se ha afirmado también su lugar en la fijación de una agenda sobre los conflictos culturales del pasado reciente. 